\title{
PORTAS ABERTAS: NOVAS POSSIBILIDADES NO ENSINO DA ENFERMAGEM PSIQUIÁTRICA*
}

\author{
Eliana Aparecida Villa** \\ Matilde Meire Miranda Cadete***
}

VILLA, E.A.; CADETE, M.M.M. Portas abertas: novas possibilidades no ensino da enfermagem psiquiátrica.

Rev.latino-am.enfermagem. Ribeirão Preto, v. 8, n. 6, p. 13-19, dezembro 2000.

Este trabalho descreve uma experiência no ensino de enfermagem psiquiátrica, em um serviço aberto de atenção à saúde mental. Os discursos dos alunos mostram o sentido desse estágio para sua formação, apontando ter sido uma experiência rica a ser mantida, pois thes permitiu conhecer o papel e a atuação do enfermeiro, desenvolver uma assistência contemplando teoria e prática, além de reconhecer o doente mental como cidadão.

UNITERMOS: ensino, enfermagem psiquiátrica

\section{INTRODUÇÃO}

Como docentes da disciplina enfermagem psiquiátrica verificamos que nem sempre, o que se pretende ensinar aos alunos tem sido possível realizar no modelo hospitalar, ou seja: assistir a pessoa portadora de doença mental como um cidadão de direitos e de deveres, que deve ser atendida na sua singularidade. Enfrentamos então, a existência de uma dicotomia entre o saber e o fazer da enfermagem.

Reportando-nos à bibliografia específica, utilizando a contribuição de alguns estudos sobre o nascimento da psiquiatria e os pressupostos que embasam o movimento da Reforma Psiquiátrica, buscamos clarear a problemática dessa assistência, relacionando-a às questões da prática da enfermagem.

No que se refere ao ensino da enfermagem psiquiátrica, vários estudos realizados com enfermeiros, fazem referência à dicotomia existente entre o discurso teórico e a prática profissional, tais como: FERRAZ (1989); AMARAL (1990); PEDRÃO (1990); FRAGA (1993); MIRANDA (1996), entre outros.

Em seu estudo sobre o ensino de enfermagem psiquiátrica no Brasil, Fernandes (1982) citada por ROCHA (1994), descreve as alterações dos programas de ensino da disciplina, que acompanharam diferentes momentos da psiquiatria, influenciados pelos movimentos de transformação como o da Psiquiatria Social, Comunidade Terapêutica, Psiquiatria Comunitária e Preventiva. Contudo, ao analisar os programas, constatou que a mudança não foi consistente, mantendo a maior parte da carga horária voltada para a psicopatologia e sua assistência. Quanto aos estágios, verificou que continuaram nos hospitais e, mesmo em raras ocasiões, quando nos ambulatórios, não se desvinculavam das atividades tradicionais. De acordo com o trabalho de COLVERO (1994), o enfermeiro nos serviços ambulatoriais, tem sido visto como limitado e restrito às características e exigências da instituição. A autora mostra a contradição no ensino de enfermagem, que vem preparando o aluno para atuar basicamente em unidades hospitalares, alterando apenas o discurso sem, contudo, repensar a proposta prática.

AMARAL (1990), entre outros, coloca que muito das dificuldades enfrentadas no exercício da enfermagem psiquiátrica, não ocorre isoladamente, mas está atrelado à lógica manicomial. Conforme descreve FOUCAULT (1987), uma lógica voltada para o silenciamento da loucura e manutenção da ordem e disciplina. Segundo este autor, a criação do hospício vem aprisionar o louco de um modo mais decisivo do que na cela, ou pelas correntes. Para AMARANTE (1995), a

\footnotetext{
* Trabalho Apresentado no $49^{\circ}$ Congresso Brasileiro de Enfermagem. 1997/Belo Horizonte, Minas Gerais, Brasil

** Professor-Auxiliar do Departamento de Enfermagem Aplicada da Escola de Enfermagem da Universidade Federal de Minas Gerais. Mestranda em Enfermagem. Endereço: Rua: Monsenhor Horta, 476 - Calafate - 30480-120 - Belo Horizonte - Minas Gerais - Brasil

*** Professor Adjunto do Departamento Materno-Infantil da Escola de Enfermagem da Universidade Federal de Minas Gerais. Doutora em Enfermagem
} 
institucionalização da loucura vai ocorrer pautada na estruturação nosográfica; na imposição da disciplina; na hegemonia médica; na construção de uma instituição médica e não mais social, em torno da qual tudo o mais foi se constituindo, inclusive as demais profissões.

Estudando a história da enfermagem psiquiátrica, AMARAL (1990) diz que esta, mesmo antes de se constituir como profissão, passou a existir enquanto atividade disciplinar no hospital psiquiátrico. Em seu trabalho, a autora faz referência às dificuldades da profissão desde seu início, destacando o despreparo do pessoal na atuação, via de regra, vigil, controladora e repressora, junto ao alienado. Mesmo em trabalhos recentes, a problemática do exercício profissional do enfermeiro psiquiátrico tem sido largamente discutida e o despreparo do pessoal, freqüentemente citado. Sabe-se dos problemas, muda-se o discurso, mas superar as dificuldades tem se mostrado um processo tão lento, quanto árduo.

É importante considerar que, em que pese a problemática da enfermagem, as questões relacionadas à assistência psiquiátrica como um todo, estão inseridas no bojo de um movimento muito mais abrangente pela sua transformação. Assim, do interior da experiência italiana de desinstitucionalização, fundamentada no discurso de Basaglia, o Brasil vem discutindo estratégias para se consolidar mudanças radicais no modelo de atenção à saúde mental.

Neste movimento de transformação, destacamos as recomendações de ROTELLI \& AMARANTE (1992), segundo as quais, não basta substituir o manicômio por outros serviços, mas há necessidade de uma mudança radical que implica na construção de novas formas de entender, de lidar e de tratar a loucura. BARROS (1994) menciona que já não basta mudar as estruturas de atendimento, mas também os paradigmas da psiquiatria, tal como ela vem se constituindo.

É dentro desta filosofia que estão sendo criados os Centros de Referência em Saúde Mental (CERSAM), pela Prefeitura Municipal de Belo Horizonte, que oferecem atendimento à urgência psiquiátrica, mantendo suas portas abertas, sem internação.

Neste contexto, a enfermagem não pode se distanciar da construção dessa prática inovadora, caso contrário, estará incorrendo na perpetuação da problemática teoria x prática. Assim pensando, iniciamos uma atividade de ensino e extensão, através da participação do docente de enfermagem psiquiátrica, num desses novos serviços.

Esta experiência, por sua riqueza, fez-nos acreditar ser de fundamental importância escutar os alunos que vivenciaram o ensino enfermagem psiquiátrica sob uma nova óptica da loucura, possibilitando-lhes descrever o real significado da vivência no CERSAM.
Portanto, realizamos este trabalho, com o objetivo de analisar a experiência de ensino em um novo serviço de atenção à saúde mental, a partir das descrições dos discentes e, através dos resultados encontrados, contribuir na reestruturação do ensino de enfermagem psiquiátrica.

\section{METODOLOGIA}

O estudo foi realizado com 23 alunos do sexto período da graduação, que cursavam a disciplina Enfermagem Psiquiátrica durante o estágio prático desenvolvido no CERSAM-NOROESTE, da Prefeitura Municipal de Belo Horizonte. É importante esclarecer que todos os alunos, além de vivenciarem o estágio neste campo de estágio, também tiveram a oportunidade de acompanhar o tratamento e a assistência de enfermagem ao paciente internado em hospital psiquiátrico.

A abordagem escolhida foi a investigação qualitativa, na modalidade do Estudo de Caso de acordo com LÜDKE \& ANDRÉ (1986). Para atingir nosso objetivo, optamos pela obtenção de um relato, solicitado aos alunos através da pergunta norteadora: QUAL O SENTIDO DESSE ESTÁGIO PARA SEU APRENDIZADO DE ENFERMEIRO?

Todos responderam por escrito, ao final do período reservado à prática no CERSAM, em sala reservada, sem interrupções. É pertinente ressaltar que nos respaldamos na Resolução 196/96 (BRASIL, 1996), em todas as fases de desenvolvimento do trabalho.

Para realização da análise, utilizamo-nos da análise de conteúdos que, segundo TRIVIÑOS (1987), é um conjunto de técnicas, que vai permitir o processo de inferência do conhecimento. A classificação dos conceitos, a codificação, a categorização, são considerados procedimentos indispensáveis. Assim, com a utilização deste método, foi possível apreender nos depoimentos dos alunos, as seguintes categorias: Uma nova concepção de atendimento em saúde mental; A cidadania como direito do doente mental; A relação entre teoria e prática; Assistência direta prestada pelo enfermeiro; Sentimentos diversos, entre eles, a perda do medo.

\section{UMA NOVA CONCEPÇÃO DE ATENDIMENTO EM SAÚDE MENTAL}

Se não podemos nos esquecer de que os problemas das urgências psiquiátricas sempre foram resolvidas pelos manicômios, também não podemos deixar de lembrar, que em inúmeros casos, esta solução só foi possível às custas da própria vida do sujeito. Seja 
pelo longo período de internação e cronificação da doença, seja pelo estígma, pela marca que passou a ter e assumir.

Assim, em meio às discussões sobre como efetivar as propostas de mudança na atenção psiquiátrica, a Secretaria Municipal de Saúde de Belo Horizonte, através da Coordenadoria de Saúde Mental, criou o Centro de Referência em Saúde Mental (CERSAM), seguindo a proposta de descentralização e regionalização do Sistema Único de Saúde (SUS).

O CERSAM, segundo SOALHEIRO (1995), tem por objetivo $o$ atendimento às urgências psiquiátricas e $o$ atravessamento da crise, em suas várias facetas, junto com o paciente, sem o afastamento da família. Neste sentido, parece-nos que a atenção psisquiátrica com as portas abertas, vem marcar uma grande diferença no atendimento até então instituído. Constitui-se em um local aberto, com estrutura e pessoal disponível para acolher as demandas daquele que chega muitas vezes, sem saber dizer a que veio e se vai ficar. Segundo BASAGLIA (1985, p.114), o doente deixa de aparecer como um homem resignado e submisso, às nossas vontades......passa a apresentar-se como um indivíduo que já não aceita ser objetivado pelo olhar do médico que o mantém à distância. É o sujeito tomando posse da sua doença e não sujeitando-se a ela.

Foram muitas as falas dos alunos mostrando que puderam identificar as diferenças no modo de tratar a doença e o doente mental. Como exemplo, nos reportaremos a algumas delas:

Mostra que as mudanças são possíveis. (6)*

Proporcionou nova visão de tratamento em

Saúde Mental. (10)

Mostrou que deve-se derrubar os conceitos

de manicomio como meio de tratamento ao doente mental. (4)

A assistência psiquiátrica hospitalar, tal qual vem se constituindo, tem no isolamento sua maior expressão e no manicômio, seu grande monumento de exclusão. Sabemos que existem momentos onde o último recurso de tratamento é a internação mas, historicamente verificamos que a busca pela hospitalização, não tem ocorrido desta forma. Aos alunos que experenciaram o estágio também no hospital psiquiátrico, foi possível identificar a problemática da segregação e em diversas falas foram feitas comparações entre o atendimento hospitalar e o atendimento aberto:

Proporcionou uma reflexão crítica em relação ao tratamento manicomial. (4) Possibilitou a diferenciação entre o tratamento hospitalar e no Cersam. (9)

Serviu para mostrar as vantagens da não

internação em hospitais. (4)

É importante ressaltar que a equipe do CERSAM, formada por profissionais de diferentes especialidades, vem trabalhando de modo coeso, dentro da mesma filosofia de resgate da cidadania e repúdio ao isolamento, discutindo com os familiares e com a comunidade, novas propostas de atendimento. Só assim, no um a um, será possível mudar a cultura manicomial tão difundida. Isto é o que chamamos de desconstruir os manicômios internos de cada um.

\section{A CIDADANIA COMO DIREITO DO DOENTE MENTAL}

O portador de sofrimento mental, enfrentando uma situação de turbulência, vê-se à frente do insuportável. Por enfrentar a situação de doença, não pode ser condenado a deterioração de sua personalidade, à perda de seus papéis sociais.

Em relação à cidadania do doente mental, NICÁCIO (1989, p.98) coloca que o modo de tratar a loucura sob a forma de exclusão, submete o sujeito internado à condição de objeto, sem voz, sem direitos, judicialmente inábil, incapaz e perigoso, configurando o louco em não cidadão. Nas palavras de CAPALBO (1994), o que importa não é a doença, mas o ser que vive esta doença e que, ao vivê-la não perde sua dimensão de ser humano, merecendo portanto, respeito, dignidade e valor na sua existência concreta.

A Reforma Psiquiátrica tem como premissa imperativa os direitos do doente mental, sua cidadania. Através de um novo modo de cuidar, segundo BIRMAN (1992), será possível surgir aquele que se oculta atrás da desrazão. Portanto, não se trata de enquadrar o portador de doença mental aos padrões socialmente aceitos, mas pensar a cidadania em termos que considerem aspectos particulares e singulares de cada caso.

Aos alunos foi possível a identificação da singularidade e a valorização do resgate do sujeito acometido por um sofrimento mental, como mostram as falas:

Proporcionou encarar os doentes mentais como seres humanos que são e que possuem seus direitos. (4)

O CERSAM ajuda o doente mental a interagir na sociedade. (6)

Proporciona ao paciente ser agente ativo

\footnotetext{
* Os números entre parênteses, referem-se à quantidade de alunos que deram respostas com o mesmo significado. As frases sem números, tiveram única expressão
} 
no processo de recuperação e de vida. (2)

Aqui o usuário é tratado com dignidade,

respeito, como pessoas. (5)

$\mathrm{O}$ atendimento prestado aos usuários permitiu aos alunos, através da vivência, o comprometimento no repasse de uma nova visão do louco e da loucura, ampliando-a para fora do estágio, para além da Escola de Enfermagem. Assim, a sociedade poderá focalizar a doença mental por outro ângulo, levando-a a uma transformação na forma de conviver com a loucura. Esta é também, uma maneira de se construir a cidadania do doente mental.

\section{A RELAÇÃO ENTRE A TEORIA E A PRÁTICA}

Se quisermos operar mudanças na assistência ao doente mental, devemos preparar os profissionais de enfermagem. Foi com esse objetivo que iniciamos o programa de ensino e extensão no CERSAMNOROESTE, cujo trabalho está voltado para diferentes alternativas de atendimento e de inserção do doente mental, ampliando suas possibilidades evitando, por conseguinte, a internação hospitalar.

Procuramos assim, investir no processo de mudança, propiciando ao aluno um espaço viável à aplicação do conhecimento, possibilitando-lhe o desenvolvimento de novas habilidades.

Voltando à literatura específica, ROCHA (1994) afirma que, para o enfermeiro atuar em saúde mental, deve ter preparo suficiente, com uma prática que não se restrinja ao hospital psiquiátrico, que o curso deve oferecer unidade de pensamento teórico, permitindo a formação de enfermeiros que apresentem uma verdadeira identidade profissional.

As assertivas abaixo apontam que os alunos puderam perceber o estágio no CERSAM-NOROESTE, como uma etapa de aplicação do conhecimento, como podemos verificar:

\section{O estágio aqui, serviu para melhor associar a teoria com a prática. (4) Muito bom passar pelo CERSAM. Tratamos de assuntos da teoria. (3)}

BASAGLIA (1985, p.103), analisando a estruturação e funcionamento do hospital psiquiátrico, coloca que diante da realidade manicomial, seria impossível evitar a nítida contradição com as teorias técnico-científicas. Constatamos então, nesta experiência, que a busca por uma identidade teórico-prática na enfermagem psiquiátrica se efetivará dentro dos novos moldes de se lidar com a loucura, nos quais a atuação do enfermeiro estará respaldada em um campo de experiências compatível com o perfil profissional que se quer formar.

\section{ASSISTÊNCIA DIRETA PRESTADA PELO ENFERMEIRO}

Podemos observar uma convergência de vários autores, entre eles IRVING (1979); TRAVELBEE (1979); TAYLOR (1992), ao colocarem que o papel do enfermeiro é de agente terapêutico, através do relacionamento estabelecido com o paciente. Contudo, para alguns enfermeiros, conforme cita MIRANDA (1996, p.80), a prática da enfermagem no hospital psiquiátrico causa um sofrimento de tal forma intolerável, que acabam por assumir as atividades administrativas, como verdadeiras ilhas de tranqüilidade possível. As dificuldades diante das demandas de estar as 24 horas ao lado do paciente, levam o enfermeiro a se refugiar na burocracia hospitalar, como identidade possível.

Diante desta realidade, o aluno ao passar pelo hospital, freqüentemente observa o distanciamento do enfermeiro em relação ao paciente, contrapondo-se esta prática, à teoria que acaba de conhecer na disciplina.

Já nos novos modelos de atenção à saúde mental, verificamos que a realidade vivenciada pelo enfermeiro no seu cotidiano é diferente. A começar pelas portas abertas do CERSAM, passando pelos pressupostos teóricos que o sustentam, sua estrutura de funcionamento e o trabalho conjunto dos técnicos e funcionários, o enfermeiro tem a possibilidade de viver uma experiência onde não necessita se refugiar nos aspectos administrativos da assistência, mas assume seu papel de agente no tratamento ao portador de sofrimento mental.

Neste contexto, a possibilidade do enfermeiro desenvolver a função terapêutica foi observada pelos alunos, conforme mostram as afirmações:

O estágio no CERSAM mostrou que o enfermeiro pode atuar de maneira efetiva junto ao paciente. (5)

Pude compreender o papel da enfermeira junto do paciente, através das consultas de enfermagem e sua participação direta no tratamento. (2)

$A$ enfermagem tem maior liberdade de atuação e maior oportunidade para trabalhar com os pacientes, desenvolvendo diversas atividades. (2)

É uma nova área de trabalho para a enfermagem. (3) 
Finalizando essa categoria, entendemos que a posição do enfermeiro em relação à instituição, bem como seu papel junto ao doente mental, vem sendo transformado. Partindo desse novo lugar, já começa a definir quais são as demandas dos clientes que podem ser respondidas pela enfermagem, assumindo efetivamente sua função terapêutica.

\section{SENTIMENTOS DIVERSOS, ENTRE ELES, A PERDA DO MEDO}

São dois os sentimentos muito presentes na história, no percurso e no ensino da enfermagem psiquiátrica: o sofrimento e o medo.

Diante da vivência-sofrimento do doente mental, pensamos no aluno: como ele experiencia esse sofrimento? como trabalha os sentimentos com os quais se defronta? Podemos ter maior clareza de tal realidade, através de um relato de experiência, nas palavras de um estagiário de psicologia, também aluno: Hoje, a grande imagem que eu tenho da loucura, para designá-la de forma breve e precisa, é a imagem do sofrimento (MARÇOLLA, 1995, p.43). E ao falar do sofrimento, o mesmo aluno denuncia o reflexo desse sentimento, na vivência de estudante: $O$ sofrimento que a Loucura nos remete é justamente esse: o de não conseguir conviver com a própria angústia, com o próprio desejo. Sofrimento este que vemos no louco e que nos remete à angústia que temos. É a partir do conhecimento desta vivência que, como docentes, poderemos auxiliar o aluno a trilhar o caminho do aprendizado, nem sempre tranqüilo, no ensino da enfermagem psiquiátrica.

Ainda preocupados com o sentimento do aluno, diversas vezes externado durante o desenvolvimento da disciplina, desejamos dar um enfoque especial à questão do medo, que percebemos e que pode ser superado durante o estágio.

A figura do louco, para quem nunca teve contato com a loucura, desperta em cada um, fantasmas de diferentes formas. É freqüente, no senso comum, relacionar a loucura à periculosidade, à agressividade, à violência. São crenças infundadas, contudo difundidas, que o aluno traz consigo e que vai se esvanecendo à medida em que se permite aproximar do doente mental e de sua realidade.

No CERSAM-NOROESTE, não há uso de chaves, suas portas permanecem abertas durante todo tempo, embora atendendo urgência psiquiátrica. As portas abertas fazem grande diferença, tanto para quem é assistido, quanto para o aluno, que se mostra a princípio, temeroso e descrente desta possibilidade. Verificamos que o usuário nem sempre está de acordo em permanecer ali.
Contudo, mesmo quando contrariado, tem sido preocupação constante ouvi-lo, tranqüilizá-lo quando possível, orientando-o da necessidade de tratamento e em relação às suas angústias e preocupações. É um momento decisivo na formação do aluno, onde o medo cede lugar à necessidade de assistir, de ajudar o outro e ali aplicar o conhecimento. Constatamos que esta atitude possibilita diminuir sua angústia e conseqüentemente, superar o medo, sentindo-se útil. Tal qual é mostrado nas colocações abaixo:

Gostei da possibilidade de poder ajudar,.....

Me senti mais livre, solta ,útil e importante

para os pacientes. (3)

O mais importante é que aqui perdi o medo

do doente mental. (7)

Ainda nesta categoria, desejamos ressaltar que a imagem plasmada no senso comum do "louco-agressivo" tem sido na prática, o produto da inabilidade de quem lida com ele, do descaso e, muitas vezes, da desumanidade com a qual é tratado. Quando se percebe ouvido, já não há necessidade de "passar ao ato", sente-se de alguma forma, amparado. E através do estágio, o aluno modificou alguns de seus conceitos:

$O$ estágio serve para mudar os mitos $e$ preconceitos. E como serve! (2)

\section{CONSIDERAÇÕES FINAIS}

Pudemos neste estudo, verificar a riqueza e importância da contribuição desta experiência de ensino, realizada no CERSAM-NOROESTE, na formação do enfermeiro.

Os alunos da graduação em enfermagem psiquiátrica, colocaram que neste campo, foi possível experenciar um atendimento à saúde mental fundamentado numa nova concepção sobre a loucura, nas propostas de tratamento que visam o resgate da cidadania; puderam verificar a participação efetiva do enfermeiro na assistência e as possibilidades de aplicação do conhecimento ainda enquanto estudantes, contribuindo na atenção à saúde mental, bem como, na desmistificação da loucura.

Assim, desejamos com este trabalho, mostrar a possibilidade de concretização de um ensino mais próximo da prática existente e embasados em reflexões coletivas sobre esta, investir na formação de futuros enfermeiros, que apresentem uma verdadeira identidade profissional: indivíduos capazes de pensar sua prática, valorizar o atendimento direto ao doente mental e sua família e que possam enfim, atuar de alguma forma, junto à sociedade, na mudança da cultura manicomial. 


\section{OPEN DOORS: A NEW POSSIBILITY IN PSYCHIATRIC NURSING TEACHING}

This paper describes a teaching experience in psychiatric nursing at an open mental health care service. Students' discourses show how meaningful and rich an experience it has been for their careers. Participating in this training has allowed them to learn the role of nurses, to improve assistance by applying both theory and practice as well as to recognize people with mental disorders as ordinary citizens.

KEY WORDS: teaching, psychiatric nursing, psychiatric reform

\section{PUERTAS ABIERTAS: NUEVAS POSIBILIDADES EN LA ENSEÑANZA DE LA ENFERMERÍA PSIQUIÁTRICA}

Este trabajo describe una experiencia en la enseñanza de la enfermería psiquiátrica en un servicio abierto de atención a la salud mental. Los relatos de los alumnos muestran el sentido de éstas prácticas para su formación profesional. Señalando la riqueza de ésta experiencia y el interés por su continuación ya que les permitió conocer el papel y la actuación del enfermero, desarrollar una asistencia teniendo en cuenta teoría y práctica, además de reconocer al enfermo mental como ciudadano.

TÉRMINOS CLAVES: enseñanza, enfermería psiquiátrica, reforma psiquiátrica

\section{REFERÊNCIAS BIBLIOGRÁFICAS}

\section{AMARAL, A. A Enfermagem psiquiátrica na} realidade brasileira: desafio entre o saber e o fazer. Rio de Janeiro, 1990. 141p. Dissertação (Mestrado) - Escola de Enfermagem Ana Nery, Universidade Federal do Rio de Janeiro.

02. AMARANTE, P. (org.). Loucos pela vida: a trajetória da reforma psiquiátrica no Brasil. Rio de Janeiro: SDE/ENSP, 1995. 143p.

03. BARROS, D.D. Jardins de Abel: desconstrução do manicômio de Trieste. São Paulo: Edusp/Lemos, 1994. $155 \mathrm{p}$.

04. BASAGLIA, F. (coord.). A Instituição negada: relato de um hospital psiquiátrico. Rio de Janeiro: Graal, 1985. 326p.

05. BIRMAN, J. A cidadania tresloucada. In: BEZERRA Jr., B.; AMARANTE. P.(orgs.). Psiquiatria sem hospício. Rio de Janeiro: Relume - Dumará, 1992. p. 71-90.

06. BRASIL. Ministério da Saúde. Conselho Nacional de Saúde. Resolução no 196/96. Brasília: Ministério da Saúde, 1996.

07. CAPALBO, C. Abordando a Enfermagem a partir da fenomenologia. Rev.Enfermagem. UERJ, v. 2, n. 1, p. 70-76, 1994.

08. COLVERO, L.A. O significado do "ser-enfermeiro" em Ambulatório de Saúde Mental. São Paulo, 1994. 117p. Dissertação (Mestrado) - Escola de Enfermagem, Universidade de São Paulo.
09. FERRAZ, C.A. Compreensão do exercício profissional do enfermeiro: uma análise fenomenológica. Ribeirão Preto, 1989. 83p. Dissertação (Mestrado) - Escola de Enfermagem, Universidade de São Paulo.

10. FOUCAULT, M. História da loucura. 2.ed. São Paulo: Perspectiva, 1987. p.459-503.

11. FRAGA, M.N. A prática de Enfermagem Psiquiátrica: subordinação e resistência. São Paulo: Cortez, 1993. 158p.

12. IRVING, S. Enfermagem Psiquiátrica básica. Rio de Janeiro: Interamericana, 1979. 293p.

13. LÜDKE, M.; ANDRÉ, M. Pesquisa em educação: abordagens qualitativas. São Paulo: EPU, 1986. $99 \mathrm{p}$.

14. MARÇOLLA, B. Sofrimento em vida-transformação. Contexto (Órgão de Divulgação do Hospital Galba-Velloso), Belo Horizonte, n. 6, p. 43-45, nov. 1995.

15. MIRANDA M.C.L. Algumas questões sobre assistência de Enfermagem Psiquiátrica de qualidade. Cadernos do IPUB, n. 3, p. 77-82, 1996.

16. NICÁCIO, M.F. Da instituição negada à instituição inventada. In: LANCETTI, A. (coord.). Saúde loucura, 1. São Paulo: HUCITEC, 1989. p. 91108.

17. PEDRÃO, L.J. Certezas e dúvidas do enfermeiro de unidade de psiquiatria de hospital geral: seu papel, sua educação. Ribeirão Preto, 1990. 96 p. Dissertação (Mestrado) - Escola de Enfermagem, Universidade de São Paulo.

18. ROCHA, R. Enfermagem Psiquiátrica: que papel é este? Rio de Janeiro: Te Corá, 1994. 140p. 
19. ROTElli, F.; AMARANTE, P. Reformas psiquiátricas na Itália e no Brasil: aspectos históricos e metodológicos. In: BEZERRA Jr., B.; AMARANTE, P. (orgs.). Psiquiatria sem hospício. Rio de Janeiro: Relume - Dumará, 1992. p. 41-55.

20. SOALHEIRO, N.I. A implantação do projeto Assistencial de Saúde Mental no Distrito Sanitário do Barreiro. In: Dispositivos de tratamento em Saúde Mental na Rede Pública: construindo um projeto. Belo Horizonte: PMBH, 1995. p. 7-13.
21. TAYLOR, C.M. Fundamentos de Enfermagem

Psiquiátrica de Mereness. Porto Alegre: Artes Médicas, 1992. 465p.

22. TRAVELBEE, J. Intervencion en Enfermaria

Psiquiatrica. Cali, Colômbia: OPAS/OMS, 1979. $257 \mathrm{p}$.

23. TRIVIÑOS, A. Introdução à pesquisa em ciências sociais: a pesquisa qualitativa em educação. São Paulo: Atlas, 1987. 175p. 